\title{
Interiority: At the Threshold
}

Paramita Atmodiwirjo, Yandi Andri Yatmo $\quad \begin{aligned} & \text { Universitas Indonesia } \\ & \text { Indonesia }\end{aligned}$

Being at the threshold offers an ambiguous spatial experience. In everyday life, one is often at the threshold between one spatial situation and another: stepping inside a space; passing through a boundary; or moving through a passage. Threshold suggests a transitional condition and represents a situation that one should cross to be on the other side, or to move into the other condition, as illustrated by Georges Perec (2008):

On one side, me and my place, the private, the domestic ...; on the other side, other people, the world, the public, politics. You can't simply let yourself slide from one into the other, can't pass from one to the other, neither in one direction nor in the other. You have to have the password, have to cross the threshold, have to show your credentials, have to communicate... (p. 37)

The idea of threshold is relevant to the discourse of interiority, as it expands our understanding of the opposing condition of insideoutside, or interior-exterior, which have become the recurring themes in many discussions on interiority. With the blurring boundaries between interior and exterior, "interior space can no longer oppose exterior; it emerges onto the threshold of becoming exterior" (Stoner, 2012 , p. 43). Threshold marks the transgression from one state to another, as well as the changes from the inside to the outside, from the interior to the exterior, from one spatial quality to another. The idea of threshold contains spatial ambivalence (Boettger, 2014), and it poses a question on where the differentiation between interior

Correspondence Address: Paramita Atmodiwirjo, Department of Architecture, Faculty of Engineering, Universitas Indonesia, Kampus Baru UI Depok, 16424, Indonesia. Email:paramita@eng.ui.ac.id 
and exterior lies.; "where does interior end and the exterior begin?" (Weinthal, 2011, p. 576). Such ambivalence eventually makes the threshold become an interesting medium in which to exercise the relationship between interior and exterior, and to investigate the spatial experience of in-between that it offers.

Threshold is particularly interesting because it defines separateness and at the same time also suggests connectedness. As mentioned by Georg Simmel (1994) in his essay Bridge and Door, the role of threshold is to "separate the connected or connect the separated" (p. 5). Being at the threshold allows us to have different perspectives toward both conditions that are separated (as well as connected) by the threshold.

From a material perspective, threshold exists in particular forms of architectural or interior elements, such as gates, portals, doors, bridges, porches or other physical forms. However, the experience of threshold needs to be interpreted beyond the physical transition from one part of space to another. Being at the threshold actually involves the subjective construct of the transitional experience, or moving between various spatial qualities.

The structure of experienced space is defined by the existence of human bodies and their actions in space (Bollnow, 2008). In particular, the understanding of transitional experience cannot be separated from the body's movements (Blundell Jones, 2015). Thus, the idea of threshold challenges our understanding of the interiorexterior relationship from the experiential perspective; it calls for investigating the interior spaces and interior processes as defined or determined by the human body, its sensorial devices and its action. This issue of Interiority attempts to address what actually occurs at the threshold - the occupation and the experience of the threshold. The contributors in this issue address the emergence of spatial ideas that define the new relationship between inside and outside, between interior and architecture.

The discourse on threshold becomes much more critical when located within the context of larger interior scale of the city. It encourages a departure from the traditional thinking on the urban environment, which often is defined by the clear demarcation between inside (interior, building) and outside (street, open spaces), with the presence of threshold as the elements separating/ connecting the inside and outside. As the boundaries between inside and outside gradually are blurring, threshold has a new meaning; the experience of being at the threshold is extended into the in-between, momentary and fluid experiences that one encounters while moving through such blurred boundaries. 
The first three articles look into how the idea of interior and architecture is merged within an urban context, leading to the emergence of various types of urban interiors. The authors look into different scales of context in which the threshold of interiorexterior, or inside-outside, works in various ways to define the new experiences.

Roderick Adams and Lucy Marlor begin the dialogue in this issue by challenging the structuralist concepts of architecture and interior as binary oppositions. They present the different approaches for inbetween spaces through the examples of flexible space (conceptual), hybrid space (adapted), reclaimed space (extended) and pop-up space (new). These types illustrate the merging of interior and exterior as defined by the occupation of the users, and the emerging types eventually offer the new urban experience. They suggest an alternative thinking on the interior materiality that is more focussed on momentary occupations than on the physical materiality defined by the interior finishes or architectural structure.

The fact that a threshold indicates both separation and connection suggests the threshold's critical role in defining the relationship between the two sides. The second paper attempts to revisit the relationship between buildings' interiors and the city's streets. Patrizio Martinelli examines how the proposed urban elements from Le Corbusier (rue corridor, Dom-ino, redents and immeuble villa) defined the new kinds of relationships between inside and outside - between the street and the building, and between public domain and domestic life. Through a series of collages, Martinelli illustrates how Le Corbusier's ideas on moving urban elements into the interior offer a new interpretation of the city's interior spaces.

Cathryn Klasto presents three case studies on kyōshō jūtaku, i.e., narrow houses in Tokyo, that illustrate the strategies to achieve dialogue between architecture and nature. Various design strategies were practised in kyōshō jūtaku to allow nature to become the mediator between uchi and soto, i.e., inside and outside. A new kind of relationship between the dwelling and the city becomes possible by creating movement and interaction between the public and the private as mediated by nature.

These three articles suggest the emergence of interior types in an urban context; each suggests different perspectives for understanding the threshold between the inside and the outside. Adams and Marlor suggested four urban interior types that emerged as a result of occupation by the users in which the insideoutside differentiation is no longer relevant or necessary. Martinelli revealed the urban interior types developed by Le Corbusier as the 
strategies for redefining the relationship between the buildings (inside) and the streets (outside). Klasto presents the types that have emerged through the existence of nature as the mediator between uchi-soto, between inside-outside and between private-public. The emergence of such urban-interior types that these three articles propose opens up possibilities for defining new kinds of interior experiences and processes within the city.

Being at the threshold allows one to have both outward and inward perspectives. Both perspectives are necessary to gain a complete understanding of the interior. The other three articles in this issue address how we understand interior spaces and processes from experiential perspectives, particularly from the inside - from within. Seeing from the inside becomes a way to reveal emergent processes within certain spatial phenomena. Seeing from the inside also allows for the revelation of various layers in which interiority is contained and emerging.

Seeing from the inside becomes important not only to comprehend the interior space as experienced, but also to reveal such interiors' emergence process. M. Mirza Y. Harahap, Kate Tregloan and Anna Nervegna examine the inside process of design as a way to reveal the emergence of interior design ideas. Through a reflective account of a design research practice, they argue for the roles of both rational and creative thinking as being the complementary aspects of the design process, as well as the importance of forward-backward thinking throughout the process for the two modes of thinking to contribute simultaneously. Seeing the design process from the inside becomes an important act by the designer to reflect on his or her position throughout the process of emerging ideas.

Seeing from the inside also allows one to define one's presence within the environment and comprehend how one acts within the interior. The other two articles address the concept of interiority as understood and experienced on a more intimate scale. Bruno Cruz Petit examines various interior spaces that emerged throughout key historical periods and extracted how such interior spaces became the representation of the relationship between spaces and individuals. He establishes a categorisation of interior space that is pertinent to the personal experience and the perception of space the spiritual, the hedonistic and the promiscuous interiors.

The process of relating one's self with the interior depends highly on the sensory systems that relate the body with the surrounding environment. Maria Sengke and Triandriani Mustikawati address the importance of seeing mechanism as a way for the human body to relate with the interior both when in static position and 
while moving. The mechanism of seeing from a particular point of observation provides the visual information within a range determined by the body position, while the mechanism of seeing while moving provides dynamic and continuous visual information.

Altogether, the articles in this issue reveal various forms of relationships among the interiors, buildings, urban elements and natural landscapes that are highly relevant in understanding and developing the contemporary urban interior. Human users have the primary role within such emerging interior types, as they define the spatial occupation, sensorial encounter and personal experience within the spaces. As Boettger (2014) notes, "An understanding of threshold spaces can make us conscious of how we move in a state of 'between-ness'"' (p. 13). This issue of Interiority attempts to present the dialogue on the state of 'between-ness' found in various scales of interior - from intimate to urban interiors. By being at the threshold, we can have a clear perspective and see such states of 'betweenness', thereby becoming aware that such knowledge is ready to be expanded and challenged to create further discourse on interiority.

\section{References}

Blundell Jones, P. (2015). The primacy of bodily experience. In P. Blundell Jones \& M. Meagher (Eds.), Architecture and movement: The dynamic experience of buildings and landscapes (pp. 96-101). London: Routledge.

Boettger, T. (2014). Threshold spaces: Transitions in architecture analysis and design tools. Basel: Birkhäuser.

Bollnow, O. F. (2011). Human space (W. Kohlhammer, Trans.). London: Hyphen Press. (Original work published 1963)

Perec, G. (2008). Species of spaces and other pieces (J. Sturrock, Trans.). London: Penguin Books. (Original work published 1974)

Simmel, G. (1994). Bridge and door. Theory, Culture \& Society, 11, 5-10.

Stoner, J. (2012). Toward a minor architecture. Cambridge, MA: MIT Press.

Weinthal, L. (Ed.) (2011). Toward a new interior: An anthology of interior design theory. New York: Princeton Architectural Press. 